\title{
Spirituality and religiosity at the junction of consumerism: Exploring Consumer Preference for Spiritual Brands
}

\begin{abstract}
This paper extends the growing research on the influence of religion and spiritualism on consumer behavior by exploring the relationship between spirituality and religiosity (intrinsic vs. extrinsic) as well as their effects on consumers' purchase of FMCG (Fast Moving Consumer Goods) brands promoted by spiritual leaders (spiritual brands). Results from an online survey of 238 Indian consumers across four food product categories (honey, cheese, biscuits and cooking oil) shows that both intrinsic and extrinsic religiosity have significant positive effects but spirituality has no significant effect on the purchase of spiritual brands. We discuss the theoretical and managerial implications of these findings as well as some limitations of our study and useful directions for future research.
\end{abstract}

\section{Keywords}

Branding, Gurus, Extrinsic, Intrinsic, Religiosity, Spirituality, Consumer behavior 


\section{1 | INTRODUCTION}

With the recent rise in the power of the emerging economies, there is growing interest in the ongoing socio-economic changes in their societies (e.g., Cavusgil, Ghauri, \& Akcal, 2003; Meyer \& Peng, 2016; Sharma, 2011). Marketing researchers in particular, are now paying attention to the impact of social contexts and norms, such as materialism (Sharma, 2011; Yang \& Stening, 2016), pragmatism (Yang \& Stening, 2013) as well as religiosity and spirituality (Arli, Cherrier, \& Tjiptono, 2016; Casidy, Phau, \& Lwin, 2016; El-Bassiouny, 2014; Jamal \& Sharifuddin, 2015) on consumer choices and behaviours (Abela, 2014; IzberkBilgin, 2012; Mathras, Cohen, Mandel, \& Mick, 2016; McAlexander, Dufault, Martin, \& Schouten, 2014). This study seeks to contribute to the growing body of knowledge on the subject by focusing on the Indian context; a place wherein religion and spirituality play a significant role in influencing norms, behaviors and actions in society.

Religion is considered to be an important dimension that impacts consumer behavior, through beliefs, rituals, values and communal faith that its members share and subscribe to (Mathras et al., 2016). Furthermore, the level of religiosity (i.e. the intensity with which an individual believes in a religion, and thus affiliates and participates in it) also causes the differences in the observed consumer behaviors (Mathras et al., 2016). It is for this reason that Engelland (2014) notes that there is an important relationship between marketing and religion, and that more systematic and direct attention must be paid to it. As religion is also an important aspect of culture, its role in the international marketing arena is rendered even more important (Engelland, 2014). That is, knowing about this antecedent can potentially help marketers to strategise and fine tune their efforts to change or influence the secondary beliefs of people; however, attempts to alter core beliefs would be much more difficult (Kotler \& Keller, 2009). And yet, Asia holds the most promise in this respect, offering a contextual landscape with multiple religious faiths. 
While aiming to contribute to this important body of management literature on context based research in Asia, we present India as our research context. While India is of global economic significance, it is also a hugely diverse, complex and an intriguing country. This offers a fertile landscape to scholars to investigate and derive meaningful insights. We also differentiate between religiosity and spirituality in this paper, which has often been overlooked in marketing scholarship, despite growing evidence about the differences between these two constructs. For example, Saucier \& Skrzypińska (2006) and Zinnbauer et al. (1997) suggest not to use religiosity and spirituality as a unitary phenomenon, as they appeal distinctly to the personality dimensions of individuals. Moreover, religion is now increasingly being considered as traditional, institutional and ritualistic; whereas spirituality is being described in contrast, as "an individual expression that speaks to the greatest of human capacities" (Pargament, 1999). This is particularly visible in the West, where people often declare themselves to be "spiritual, but not religious" (Huss, 2014).

This study aims to make three distinct contributions. First, this study not only treats religiosity and spirituality as separate constructs, but also explores their relationship with each other; thereby contributing to this discussion in the Asian context. Second, this study also draws a distinction between intrinsic versus extrinsic religiosity, which is important. This is because attributes to the two behavioral orientations - intrinsic religiosity and extrinsic religiosity - are distinct and are thus likely to influence the consumer behaviour differently. Both these contributions will help extend the growing research on the impact of religion on consumer behavior (Arli et al., 2016; Casidy et al., 2016; Izberk-Bilgin, 2012; Mathras et al., 2016; McAlexander et al., 2014). Third, this study investigates the influence of spirituality on the purchase of FMCG products being branded and promoted by Indian spiritual gurus. The research then also makes a direct contribution to the literature on the consumption of spirituality, which seeks more attention of marketing scholars (Shaw \& Thomson, 2013). 
We begin this paper with a review of the current literature on religiosity and spirituality, and their influence on consumer attitudes and behaviours, followed by a discussion and development of specific hypotheses on the impact of intrinsic and extrinsic religiosity and spirituality on the purchase of FMCG brands promoted by spiritual leaders in India. Next, we describe an online survey with 238 Indian consumers across four food product categories (honey, cheese, biscuits and cooking oil) used to test these hypotheses. We discuss our findings and their implications along with the limitations of our study and some useful directions for future research.

\section{2 | THEORETICAL BACKGROUND}

\section{1 | Religiosity and spirituality}

Zinnbauer et al. (1997) states that often religiosity and spirituality are used interchangeably and inconsistently by scholars. This is despite the fact that, in the West, a clear distinction has emerged between these two constructs (Hill et al., 2000; Pargament, 1999). Furthermore, it is not uncommon to hear people declaring that they are "spiritual, but not religious" (Huss, 2014), and the number of people with such beliefs is growing in USA and Europe alike (Berghuijs, Pieper, \& Bakker, 2013). For example, in USA alone, 27\% of the population subscribe to being spiritual and not very religious, which is up $8 \%$ in the last five years (Lipka \& Gecewicz, 2017). Likewise, in 2012 about one-fifth of Australians reported themselves as spiritual but not religious (Debien \& Calderwood, 2016). Apart from this, there is also a worldwide general trend wherein people are turning away from the church and religion; becoming atheists and agnostics instead (Bullard, 2016). The phenomenon of turning away from religion is more profound in Europe when compared to USA, as Americans score higher on religious beliefs and activities (Andersen, Gundelach, \& Lüchau, 2008; Voas \& Crockett, 2005). In a 2010 survey, just 51\% of the population in EU's 27 
countries mentioned that they believed in God, while more than a quarter suggested that they have no religion (Ames, 2013; Crabtree, 2015). In some countries, such as Estonia, Sweden and Czech Republic, the proportion of people following God fell below $20 \%$ as more people believed in the existence of "some form of spirit or life force", a thought closer to spirituality (Ames, 2013).

One reasons for the above trend in drawing a distinction between religion and spirituality is the rise of secularism (Zinnbauer et al., 1997). There is also a popular disillusionment with the institutionalized version of many major religions (involving formal structures, rules and rituals) that is perceived as excessively dogmatic, prescriptive, and an obstacle to "personal experiences of the sacred" (Zinnbauer et al., 1997). This disillusionment and disenchantment with religion in the West was accentuated by modernization and scientific queries that provided alternative explanations to our existence, resulting in the bourgeois revolution and rapid erosion of traditional values (Huss, 2014; Lee, 2003; Pargament, 1999).

Notwithstanding the above trend, there are still a vast majority of people who state that they are both religious and spiritual. For example, $48 \%$ of the US population still identify as being both religious and spiritual while only $6 \%$ say that they are religious but not spiritual (Lipka \& Gecewicz, 2017). This is because, essentially, spirituality was the core of any religion, until the popular conceptualization of spirituality underwent a major shift in the last few decades and people started to make distinction between 'being religious' and 'being spiritual' for the reasons discussed above (Huss, 2014). At the same time, there has been a growing realization that "people involve themselves in religious activities for many reasons, not all of them spiritual" (Pargament, 1999). 


\section{2 | Intrinsic vs. extrinsic religiosity}

Allport and Ross (1967) differentiate the motivation for religiosity into two: intrinsic motivation and extrinsic motivation. To some individuals, religion provides a way to lead their daily life, and thus they are intrinsically motivated. For several others, particularly most disenfranchised people, religious congregations are sources of social support, seeking comfort, or even meeting their personal needs, such as networking (Arli et al., 2016; Pargament, 1999). So, in the latter case, the religious motivation can be said to be extrinsic. That two motivations are distinct has been demonstrated by studies where scholars (e.g. Arli \& Tjiptono, 2014; Patwardhan, Keith, \& Vitell, 2012; Vitell et al., 2015) even show a negative correlation between intrinsic and extrinsic religiosity. It would then not be too farfetched to suggest that at least intrinsic religiosity (refers to intrinsic religious orientation) and spirituality would be related, as the latter was to be the core of any religion (Stillman et al., 2012). Some religions have done better than others in preserving this link while others may have lost it due to generations of decadence and institutionalisation of dogmatic beliefs (Pargament, 1999). In this paper, the authors also draw a distinction between intrinsic and extrinsic motivations for religiosity.

\subsection{Consumption of spirituality}

While spirituality has become increasingly distinct to religion and has connected to subjective, individual, metaphysical, and experiential realms, the binary distinction between the spiritual and the material has become blurred (Huss, 2014). As the idea of spirituality has been "socially constructed, transmitted and reinforced", it has resulted in the New Age culture which in turn has produced novel cultural commodities (Huss, 2014). The concept of spirituality has itself broadened from concerning metaphysical and higher consciousness to include various aspects of mind and body well-being. Hence, the phrase 'mind-body 
spirituality' is almost omnipresent and now concerns matters of physical and mental health (Huss, 2014). It now encompasses a very long list of products and services, such as yoga and meditation sessions, martial arts, spiritual and self-help discourses, spiritual counselling and mysticism, vegetarian and organic diets for spiritual cleansing, traditional massage techniques as spiritual healing and spiritual tourism, to name a few. Thus, spirituality seems to have well and truly embraced capitalism.

Empirical research (such as Arli et al., 2016; Casidy et al., 2016; Stillman et al., 2012) suggests that religiosity, which is deemed to be closely related to spirituality, does negatively impact consumerism and immoral behavior. The fact that spirituality has embraced consumerism should be disconcerting as disenchantment from capitalism was one of the causes for its popularity and distinctiveness to religion. Nonetheless, in the past, there would have been similar expectations from religion, except it increasingly accepted consumerism and turned corporeal. Scholars (Einstein, 2008; Moore, 1995; Stout, 2009) have discussed at length about the sophistication of marketing of religious products (such as books, jewellery and music) and making consumers experience religion using popular culture. The same can now be said about spiritual products and services, even to a larger degree.

The commercialization of spirituality in the present form and its appeal to Western consumers has been prevalent for several decades now. The growth in such activity followed India's independence when its Yogis and spiritual/religious gurus travelled abroad, establishing their missions and teaching spirituality firsthand. Over time, the products and services of spirituality have become increasingly sophisticated as they tries to appeal to a more diversified set of consumers. Yet, the growth of spiritual consumerism in India, and particularly for FMCG products, is a relatively recent phenomenon. 


\section{3 | RISE OF SPIRITUAL BRANDS IN INDIA}

There are several spiritual leaders (known as gurus) in India, who draw their preaching and spiritual techniques from ancient Indian scriptures that also form the basis of the Hindu religion. However, these gurus distinctively and assiduously project themselves as spiritual leaders, and not religious figures (Jaggi \& Ghosh, 2017; Kumar, Jain, Rahman, \& Jain, 2014). Some of these prominent spiritual gurus (such as Baba Ramdev of Patanjali Yoga or Sri Sri Ravi Shankar of The Art of Living Foundation) have taken a lead in branding and promoting daily consumable goods (including food items and herbal products) (Bhatt, 2016; Sanjai \& Pradhan, 2016). These groupings or organizations are symptomatic of traditional religious groupings with loyal and committed members, but also embrace consumer mentality (Bruce, 2002; Shaw \& Thomson, 2013). Therefore, these spiritual groups have mass followings in India and abroad, and it is reported that the sale of their products has increased phenomenally over the past few years.

The above speaks to the very rapid societal change that India has seen since the turn of the century. This has been primarily accredited to the strong influence of capitalism that was brought in by globalization and economic liberalization in 1991. In the last few years in India, there has been a spike in the sales of FMCG products being branded and promoted by spiritual gurus (Maheshwari, 2017; Mitra, 2017). The growth of these branded products has been so steep that it has now started to rattle MNCs and large domestic companies that have been well-established in India for several decades (Dutta, 2017). This has intrigued the top management teams of MNCs and domestic companies, prompting them to re-think their strategy and marketing (Malviya, 2017).

The staggering rise of these FMCG products branded and promoted by spiritual gurus can certainly be accredited to the institutional support that they have received (or are still 
receiving) from the federal government and several state governments in India (Sardana \& Zhu, 2017). One of the primary causes of the institutional support has been the sweeping phenomenon of right-wing nationalism over the past two decades, and the complete majority that the mainstream right-wing party (along with the near annihilation of opposition) is currently enjoying for the first time since independence. Yet, the fact that these spiritual gurus are able to promote their products and increasingly gain market share, reflects the changing patterns of consumption and consumer behavior. Hence, there is an urgent need and a compelling case to bridge this gap in understanding if the purchase decisions by Indian consumers are influenced by their religious and/or spiritual disposition.

\section{4 | CONCEPTUAL FRAMEWORK AND HYPOTHESES}

\section{1 | Spirituality, intrinsic religiosity and purchase of spiritual brands}

While Asian spiritual philosophies may have caused and precipitated religiosity versus spirituality debate in the West over the last couple of centuries, Asian consumers may not necessarily see such a bipolar distinction between religion and spirituality as in most Asian societies, modernization and scientific temper co-exists with tradition (Lee, 2003). For instance, many Indians, who have grown up practicing familial traditions and spiritual philosophies that underlie institutionalized religious practices, are hesitant to completely renounce their religious and cultural moorings. This is not to suggest that disenchantment with the dogmatic and regressive religious ideas and social norms have not existed in India. In fact, many social reformists in modern India have worked assiduously to abolish several regressive practices in Hinduism, a struggle that still continues. Yet, for the majority of Indians, including those who are well-educated and scientifically-minded, the underlying spiritual philosophies represent a way of life, and as such, its deep connection to personal religious beliefs still pervades. 
Therefore, intrinsic religion and spirituality are not only likely to be correlated in the Indian context, it is also expected that the purchase of products promoted by spiritual gurus will be influenced by both spiritually-oriented and intrinsically religious people in India. It also rests on the observation by Mathews (2000) that there is a deep personal significance for spiritual consumers in making a choice that is reflective of their identity. This notion is in keeping with the accepted argument in the consumer behavior scholarship that "consumers often use goods to help define and construct their personal and social identity" (Fitzmaurice \& Comegys, 2006). Accordingly, we hypothesize as follows:

H1: Intrinsic religiosity has a positive association with the consumers' purchase of the brands promoted by spiritual gurus.

H2: Spirituality has a positive association with the consumers' purchase of the brands promoted by spiritual gurus.

\subsection{Extrinsic religiosity and purchase of spiritual brands}

In addition to the India's complex view of spirituality and religion, its eastern culture and philosophy is relatively more conforming to societal norms and expectations (Wong \& Ahuvia, 1998). In contrast, in Western cultures, people tend to act or behave out of their individual and personal preference (Wong \& Ahuvia, 1998). So, there is a greater tendency among people in India to behave and act in a certain manner that is expected of them and in keeping with the tradition. This aspect is also likely to reflect on the religious orientation of the public in general. Indian people are therefore not purely self-motivated to take part in various communal congregations or celebrations of religious festivals and events, but their choices are also influenced by firmly established social expectations and norms.

In the present context, wherein the gradual rise of right-wing sentiments in the country has fuelled majoritarian Hindu identity and nationalism, conforming to this phenomenon can 
translate into purchase behavior by certain consumers. People who demonstrate high extrinsic religiosity and are inclined to partake in religious and/or spiritual congregations will demonstrate stronger desire to buy things that they deem is reflective of their beliefs, following, and ethos. This behavior may help them demonstrate a stronger connection to religious grouping, and thus allow them to be more appreciated by members of their groupings and like-minded people. Hence, our next hypothesis, as follows:

H3: Extrinsic religiosity has a positive association with the consumers' purchase of the brands promoted by spiritual gurus.

Figure 1 summarizes all the three hypotheses.

\section{[Insert Figure 1 about here]}

\section{5 | RESEARCH METHODOLOGY}

\section{1 | Research setting}

As a diverse religious society, India is a useful setting to investigate the consumers' purchase behavior towards the brands promoted by spiritual gurus. With almost $80 \%$ of India's population as followers of Hinduism (CIA World Factbook, 2017), a large number of Hindu spiritual gurus and their brands are capturing the Indian FMCG market. The most notable brands are promoted by Baba Ramdev and Sri Sri Ravi Shankar. The reasons to study brands promoted by these two popular spiritual gurus are: 1) their huge popularity in India and worldwide; 2) their close association with the current political disposition at a federal level; and 3) their brands making massive headlines with regards to acceptance and growth among consumers in the FMCG segment.

These gurus have a large religious base of mostly Hindus. These followers may have intrinsic or extrinsic religious orientation. Many Indians also follow them in the quest of 
spiritualism, as these gurus consciously project themselves as spiritual leaders (rather than religious leaders). India is the second most populous nation in the world with approximately 1.3 billion people (World Population Review, 2017). Furthermore, India is home to the largest Hindu population in the world and a country of true cultural diversity. The Indian economy is growing faster than many other emerging economies of the world with a $7 \%$ growth rate between 2014 and 2016 (CIA World Factbook, 2017). The GDP per capita in 2016 was $\$ 6,600$, with a GDP household end user consumption of $60.8 \%$.

\section{2 | Measures}

This study designed a questionnaire as a survey instrument, where the measures of each construct were adapted from validated scales reported within the literature. To generate measurement items for each construct, prior research in this scholarly stream was reviewed, and an initial list of items was compiled. One of the early papers by Allport and Ross (1967) developed the scale of intrinsic religiosity $(I N T R)$ and extrinsic religiosity $(E X T R)$. In our study, we adapt the scale of INTR and EXTR from Arli et al. (2016), Darvyri et al. (2014), and Maltby (1999). Our preference for this scale, originally developed by Allport and Ross (1967), rests on the strong argument provided by Vitell (2009) in favour of distinguishing between extrinsic and intrinsic dimensions of religiosity, particularly in business and marketing research.

Kapuscinski \& Masters (2010) suggest the need to incorporate transcendent elements in a spirituality scale. Their theory builds on the premise that there are growing numbers of people who consider themselves spiritual but not religious, and that we need to capture this in the scale. Since our conceptualization on spirituality and religiosity is along similar lines, we chose to adopt their approach. The spirituality (SPRT) was thus measured by a scale primarily adapted from Delaney (2005), but also looking to Hatch, Burg, Naberhaus, and Hellmich 
(1998) and Piedmont (1999). The wording of the variables in the scales was revised in the context of this study. For example, a statement "I go to church because it helps me make friends", is revised to "I go to a religious service because it helps me to make friends" (where a religious service in Hindu context will be a bhajan, kirtan, jagrata, or something else; but, similar to a service like a 'mass' in a church).

Likewise, due care was given to the choice of variables in each of the scales (INTR, EXTR, and SPRT) ensuring that they are best reflective of the Indian context. For example, there are several religious leaders and/or spiritual gurus, each having a large following. Similarly, there are several popular and widely viewed TV channels in India (e.g. Aastha, Bhakthi, Sanskar, etc.) that broadcast religious songs and sermons by various religious gurus all throughout the day. So, capturing these aspects unique to India is important. The background of all the authors (i.e. born and brought up in India with a complete understanding of Hinduism and other religions of India) helped in making judicious selections for each of the scales. Despite this, the scales were pilot-tested and EFA performed, as will be discussed later. Finally, the scale for the purchase behavior of the spiritual guru brands was adapted from Arli et al. (2016). This scale was also customized in the context of this research in India, viz. purchase of various food items.

A pilot survey of 54 respondents was conducted in which the respondents completed the anonymous survey on a printed questionnaire. One case was discarded due to large number of missing values. An exploratory factor analysis (EFA) was used to test the scales used in the questionnaire. Scale reliability was tested using the Cronbach alpha of each construct.

\section{3 | Sampling and data collection}

The sample for the main study was collected using largely a convenience sampling technique. For this, the anonymous survey was then designed on an online platform, 
www.surveygizmo.com. The online link was shared among a personal social network, which had a cascade effect. We received 228 complete responses from the online survey. All the incomplete responses were discarded. We got 21 anonymous responses filled in hard copy prints. This made it a total of 249 responses. Next, we discarded the respondents who did not share the same primary faith or religion (i.e. Hindu religion) as that of the two prominent spiritual gurus whose brands we decided to choose for this study, namely 'Patanjali' promoted by Baba Ramdev and 'Sri Sri' promoted by Sri Sri Ravi Shankar. This left us with a total of 238 responses and allowed us to control for religious diversity in our sample. The age of the respondents ranges from 21 to 40 years. The education level of the respondents is approximately equal between graduates and post graduates. All respondents belong to an Indian geography, primarily located in urban settings. Table 1 shows the sample profile.

\section{[Insert Table 1 about here]}

\section{6 | DATA ANALYSIS AND RESULTS}

\section{1 | Reliability and validity}

We began our data analysis by testing the reliability of all the scales by first using coefficient Cronbach alpha and found all of them higher than the recommended value of 0.70 (Hair, Anderson, Tatham, \& Black, 1992), as shown in Table 2. We also calculated the composite reliability (CR) and the average variance extracted (AVE) for all the scales using confirmatory factor analysis (CFA), as shown in Table 3. All the AVE values are higher than 0.50 , hence all the scales show high convergent validity, and the square of all the AVEs for each construct is higher than its correlations with all the other constructs, which shows discriminant validity (Fornell \& Larcker, 1981).

[Insert Table 2 \& 3 about here] 


\subsection{Dependent variable}

To capture the respondents' buying behavior of the brands promoted by the spiritual gurus (BPSG), we considered four questions. Each question was about a choice regarding a food product that is consumed in India and commonly offered by the spiritual guru brands as well as other brands (owned either by a domestic company or MNC) in the Indian market. Food choices are also closely related to religious and spiritual dispositions of the individuals (Jamal \& Sharifuddin, 2015). The food products chosen were honey, cheese, biscuits and cooking oil as these food products are commonly consumed among the educated, middle class in urban India, who were also our primary respondents. Each question then had a total of five choices that respondents had to choose from. Of the five choices provided, one was Patanjali, second Sri Sri, two more popular brands for that particular product, and the fifth choice as 'others'. The popular brands owned by domestic or multi-national companies, given as alternate choices across four different food products in the study, were Dabur, Himalaya, Britannia, Amul, Parle, Saffola, and Sundrop.

The factor scores were calculated using the respondents' answers to the four questions. For example, if a respondent chose either Patanjali or Sri Sri for all the four questions, the factor score is '4'. Similarly, if a respondent did not chose Patanjali or Sri Sri on any of the four questions, then the factor score of the respondent is ' 0 '. For all the other combinations of the brands, the factor score is a number between 1 and 4 . Next, we conducted a set of data analysis using multivariate analysis of variance (MANOVA), univariate analysis of variance (ANOVA), and multinomial logistic regression (MNL) to test our hypotheses.

\subsection{Multivariate analysis of variance (MANOVA)}

We used INTR (intrinsic religiosity), EXTR (extrinsic religiosity), and SPRT (spirituality) constructs as dependent (Response) variables. BPSG was used as a fixed factor (Contrast) 
with two levels. The level one was the respondents who shows no BPSG, and level two was purchase behavior of one or more brands. In order to conduct the MANOVA, we first test the normality assumption for the dependent factors using the skewness and the PP plot. The skewness and visual inspection of the PP plot for the three factors was found satisfactory. The Wilks' Lambda was found significant $(\mathrm{F}=286.44, \mathrm{Sig}<0.001$, Partial Eta Squared $=0.79$, Observed Power $=1$ ). Table 4 summarises the univariate tests statistics.

\section{[Insert Table 4 about here]}

\section{4 | Multinomial logistic (MNL) model}

In order to establish the causality between the key constructs and BPSG, and to test the degree of association with BPSG, we developed a MNL model as a post-hoc analysis because our dependent variable is nominal with more than two levels (Greene, 2003). In this study, $B P S G$ was tested for four food products using four different questions with each respondent. Hence, each respondent could choose brands promoted by spiritual gurus for zero to four products. The BPSG was coded in three levels in line with the degree of association of respondents. The BPSG was coded as None $\left({ }^{6}=0\right.$ ') if the number of products for BPSG was zero, One ('=1') if the BPSG was one, and More ('>1') if the BPSG was for more than one food products. A total of 159 respondents showed None for BPSG, 52 respondents showed One for BPSG, and 27 respondents showed More than one for BPSG. We also developed three levels for INTR, EXTR, and SPRT. For each construct, the factor scores above 5 were coded as High, 4 to 5 were coded as Medium, and less than 4 were coded Low. The dependent variable is again BPSG. The model assumed that the INTR, EXTR, and the SPRT constructs have a causal relationship with the BPSG. Table 5 and 6 summarise these findings.

The criteria validity shows the predictive power of the model. The Nagelkerke Pseudo $R^{2}$ is observed as 0.29 , which confirms the predictive validity of the model. The MNL model is 
statistically significant with Chi-square as 64.61 at a significance level of $5 \%$. The classification table shows $68.90 \%$ as the percentage of a correct prediction. The value of Wilks' Lambda indicates that there is a significant effect on the factors. The three hypotheses were tested using F statistics and significance values (Hair, Black, Babin, \& Anderson 2010) for each construct. INTR and EXTR show significant positive associations with BPSG, therefore $H 1(\mathrm{~F}=7.47, \mathrm{Sig}<0.001)$ and $\mathrm{H} 2(\mathrm{~F}=7.88, \mathrm{Sig}<0.001)$ are supported. However, SPRT does not have a significant association with $B P S G$, hence we $H 3(\mathrm{~F}=0.01, \mathrm{Sig}=0.92)$ is not supported.

\section{[Insert Table 5 \& 6 about here]}

Post-hoc analysis of these findings (McFadden, 1974) offers some useful insights. First, EXTR is statistically significant at High level for BPSG as One $($ Beta $=+2.20$, Sig $=0.004)$. High and Medium levels of EXTR were referenced to Low level. The ' $>1$ ', and '=1' levels of BPSG were referenced to ' $=0{ }^{\prime}$. The $B P S G{ }^{\prime}=1^{\prime}$ is more likely to be preferred (by High EXTR than Low EXTR) in comparison to $B P S G{ }^{\circ}=0$ '. The reference level for the EXTR and BPSG were Low, and None respectively. The 'BPSG equals to One' is more likely to be preferred (by High EXTR than Low EXTR) in comparison to 'BPSG equals to None'.

Similarly, INTR was observed statistically significant at High level for BPSG as More $($ Beta $=1.32, \mathrm{Sig}=0.05)$. The High and Medium levels of INTR were referenced to Low level. The ' $>1$ ', and ' $=1$ ' levels of BPSG were referenced to ' $=0$ '. The BPSG ' $>1$ ' is more likely to be preferred (by High INTR than Low INTR) in comparison to BPSG ' $=0$ '. We did not find the beta statistically significant for any levels of SPRT. The key finding of the MNL can be summarized as suggesting that the degree of BPSG is different for the INTR, EXTR, and SPRT. Alternatively, one can state that the SPRT, EXTR, and INTR showed, no, moderate, and high degree of association with BPSG respectively. 


\section{7 | DISCUSSION AND IMPLICATIONS}

\section{1 | Conceptual contributions}

Our literature review showed a growing interest in the impact of religion on consumer attitudes and behaviors (e.g. Arli et al., 2016; Casidy et al., 2016; Izberk-Bilgin, 2012; Mathras et al., 2016; McAlexander et al., 2014). However, little attention has been paid to the distinction between intrinsic and extrinsic religiosity as well as their contrast with spirituality (Shaw \& Thomson, 2013). We address this gap by investigating the influence of these factors in the consumption of FMCG goods branded and promoted by spiritual leaders in India.

The popularity of Yoga, Indian religious sects or missions (e.g. ISKCON) and growing fan-following of several self-proclaimed yogis or self-help Indian gurus (e.g. Deepak Chopra) in the West is testament to the growing popularity of spiritualism and spiritual products. The consumers choosing such products/services do not base their decisions based purely on the price, quality and functionality of the product, but also on social, cognitive and affective factors (Ladhari \& Tchetgna, 2016). Therefore, it is critical to find out if religiosity and/or spirituality have any role to play in the purchase behavior of consumers in general in India, which itself has now embraced capitalism in all earnest. It is important not just from academic point of view, but also very useful for marketing and strategic executives from the companies and industries where brands are promoted by spiritual gurus is palpable in India.

In this study, we found that intrinsic religiosity is highly correlated with spirituality in the Indian context. In particular, a vast majority of people reported attending a religious place regularly, following religious beliefs and rituals, reading religious books, and praying for their inner peace. These behaviors and actions suggest that people in India are intrinsically motivated towards their religion, despite them reporting less enthusiasm towards following a particular religious guru or listening to their sermons on TV or radio. Likewise, a majority of 
the individuals report that they are spiritually oriented in their belief in a higher power/universal intelligence to which they feel connected. They also meditate to gain access to their inner spirit and feel that spirituality provides them with inner strength. This finding is not surprising as several New Age spiritual concepts are anchored in old Hindu philosophies. Therefore, an Indian person with a spiritual orientation and knowledge of Hindu philosophies will be intrinsically drawn to the religion and will be able to connect to it. This will be despite his/her (favourable or disconfirming) orientation to ritualistic and dogmatic traditions within Hinduism that has crept into the society over the last two thousand years.

It is also important to note that in our study a vast majority of people in India reported that they do not attend religious services for any of the extrinsic motivations, such as interacting with people, making friends and feeling socially secured, or even spending time praying in a communal setting. Despite this, we observe that there is a strong correlation between extrinsic religiosity and intrinsic religiosity. This is because it is quite natural for these people with extrinsic religious motivations to demonstrate behaviors in a society that is reflective of their personal identity. Hence, these individuals' indulging in acts that are usually related to an intrinsically motivated person, such as going to a religious place, following rituals, and praying for inner peace or simply following the tradition.

Interestingly, this study did not find a strong correlation between extrinsic religiosity and spirituality in the Indian context. This could be because some people who demonstrate high extrinsic religiosity may be more willing to follow the religion for extrinsic social motives or for the sake of complying with old traditions rather than appealing to higher consciousness. These people with extrinsic religious orientations may also be willing to do activities that they believe are religious in nature; though, some of those activities may relate to intrinsic religiosity, as indicated above. Even so, this may not necessarily translate into spiritual actions and deep thinking processes that, in turn, translate into meditating or appealing to 
higher consciousness. For example, an extrinsically religious person motivated to conform to social and traditional norms is more easily persuaded to chant ceremonial prayers and follow ritualistic customs, whereas an intrinsically religious person is more likely to be self-directed to pray (not necessarily chanting ceremonial prayer) and meditate for higher consciousness.

Thus, people could be classified as one of the following four types based on their religious and/or spiritual orientation: 1) those following religion intrinsically and/or extrinsically as it was part of their upbringing and they simply tend to respect and follow it as per social norms; 2) those who may not necessarily be religious, but seek to project themselves as religious for their self-interest; 3) those who are intrinsically religious and spiritually motivated and find deep connection between the two; and 4) those who are devoid of religious orientation but are only spiritually motivated. In the former two categories, there is more possibility of association of extrinsic religiosity with intrinsic religiosity, but not necessarily spirituality. Whereas the latter two categories, particularly the last one, are comparatively less likely to subscribe to practices that are of extrinsic orientation.

The above explanations regarding religiosity and spirituality in the Indian context also help us in understanding if any of these factors contribute to the increasing market share of consumable items being branded and promoted by the spiritual gurus. The findings suggest that high intrinsic religiosity is significantly and positively correlated with the purchase choice for such items branded by spiritual gurus. The intrinsic religiosity factor stands out in particular when individuals are buying more than one product (of a total of four listed food products in the survey) that is being branded and promoted by a spiritual guru. Extrinsic religiosity is also said to be positively correlated with such a choice by the consumers, particularly in those instances where individuals are consuming limited (i.e. only one out of four) products being sold and branded by a spiritual guru. In contrast, spirituality does not show any correlation with the purchase decision of consumable products branded and 
promoted by the spiritual gurus. These are interesting outcomes that can only be interpreted and understood by realizing the social context of India.

These gurus (such as Baba Ramdev and Sri Sri Ravishankar) promoting their self-branded products have essentially positioned themselves as 'spiritual gurus', yet their primary disposition is religious. In more recent times, they have also forthrightly lent their support to the right-wing political party that appeals to the Hindu majority (Kothawade, 2015). Therefore, despite their own positioning as 'spiritual gurus' or 'yoga gurus', they are widely perceived as religious gurus as well (Kothawade, 2015). It is then not difficult to fathom that their brands are not only more appealing to people with high intrinsic religiosity. Furthermore, in the past few years, they have been able to rapidly increase their outreach to this constituency by tacit institutional support, as reported widely in popular media (Deka, 2017). Their earlier limited outreach could be due to a variety of reasons, including limited institutional support they may had before. Extrinsically religious people's demonstrating limited preference (i.e. no more than one product of a total of four) to buying products by spiritual gurus can be attributed to the nature of consumable items that were selected for this study, i.e. food items that are usually consumed in private. And, intrinsic religiosity is likely to be a more resilient motivation to demonstrate strong affiliation with a religion, than compared to more perfunctory extrinsic religiosity. This is in keeping with the concept that stronger social identity or affiliation to a group can influence purchase behavior (Bartels \& Hoogendam, 2011; Wong \& Ahuvia, 1998). Hence, intrinsic religiosity has a strong influence when individuals buy a greater number of products branded and promoted by spiritual gurus.

This study also supports the arguments put forth by Mathews (2000) who suggests that the preferences that are relating to being spiritual are of immense personal significance, and not dictated by communal faith. This is manifested in the non-significant relationship between spirituality and preference for products promoted by the spiritual gurus, who are also 
widely perceived as religious leaders. Thus, consumers who are more spiritually oriented (whether they have intrinsic religious orientation or not) are less likely to be impressed with the spiritual leaders who are strongly disposed towards right-wing religious sentiments. This could be one reason that spiritually oriented people show less affinity to purchasing brands promoted by these spiritual gurus.

Religiosity and/or spirituality can define core values of individuals providing consistency to their frame of reference (Arli et al., 2016; Katz, 1960; Shavitt, 1989). This frame of reference when interacting with the identity goals (public or private) will likely impact choices that they make (Snyder \& DeBono, 1985). By using SPRT, EXTR, and INTR as separate constructs to understand the purchase of consumable products branded and promoted by spiritual gurus, this research makes a concerted effort to make contributions by progressing scholarly literature on the functional theory of attitude and integrating it into the academia on religiosity and spirituality.

As our research context is India, this study also contributes to the call by several international business scholars (such as Tsui, 2004; Meyer, 2006) to undertake a high quality and context-specific study in an Asian context. The objective of such a call is to fill our knowledge gaps of the unique context in Asia; to better understand what most impacts businesses in such a context. That our study captures and incorporates context in our theoretical analysis and discussion is also an important contribution.

\section{2 | Managerial implications}

This study also offer some promising implications for marketing managers. Notably, a strong majority of MNCs operating in India have been sensitive to the cultural and religious sentiments of its people. For example, Nestle does not sell 'Beef' flavoured Maggi noodles in India. These MNCs were also not oblivious to the strong hands of institutional intervention 
and nationalistic sentiments of the public that would adversely impact their businesses in India. Yet, for the first time, MNCs, domestic and FMCG companies that sell consumable food items are facing fierce competition and a real threat to their market share from unexpected quarters, i.e. brands promoted and sold by Indian spiritual gurus. These relatively new entities are aggressively marketing their products by appealing to cultural heritage, tradition, purity, naturalness and nationalism (i.e. home-grown brand caring for people versus foreign brands only interested in profits). While domestic companies have also used one or several types of appeal to promote their brands, these new entities by Indian spiritual gurus with millions of followers have considerably accentuated these appeals to their advantage. In addition, the new age entities are also riding on the growth of right-wing majority religious sentiments. This new phenomenon, great in scale and implications, is therefore useful for marketing and management professionals in exploring and fully understanding the impact of religion on consumer preferences in India, one of the largest and growing markets in Asia.

Religious people showing a proclivity to the brands by religious 'spiritual' gurus of India demonstrates socially conscious behaviors, which may be in keeping with resurgence of Hindu nationalism in India, and seeks to be a topic for future investigation. In the context of religion, consumption, particularly of food items, is often influenced and guided by religion (El-Bassiouny, 2014; Jamal \& Sharifuddin, 2015; McAlexander et al., 2014). Religious heads and institutions can therefore play an important role in influencing followers' personal preferences as the gurus are in a position to relate consumption to a particular ideology (Arli et al., 2016). Just as religious leaders can label a particular type of food as taboo or immoral (such as beef or pork in the Indian context), they can also prompt people into consuming a food as labelled as divine, natural, pure or blessed. They can even ascribe products as being closer or belonging to the tradition or culture, as a point of differentiation. In future, with 
possibilities of investigating these diverse aspects along with the likelihood of including some demographic measures, researchers can gain a more granular understanding of the subject.

\section{3 | Limitations and future research}

Often researchers work under constraints and limitations and this research is no different (Arli et al., 2016). Our sample in drawn from the urban population in India, and the respondents have primarily been recruited using immediate networking and its cascade effect using social and digital media (such as WhatsApp groups). Therefore the sample is not an exact representation of the demographics in India. Despite this, our choice to focus on the urban educated population was motivated by the fact that the sale (in terms of total value) of FMCG products is still driven by this group, notwithstanding the growing sales in rural India (Lu, Yiu, \& Soman, 2016; Nielsen, 2012; Singhi, Jain \& Sanghi, 2017). Another limitation of the study is that the sample size is also low when compared to the population of urban India. Future studies should strive for a broader and a more representative sample, if possible. In addition, it would be useful to extend this study to other countries where spiritual or religious leaders also promote consumer product brands, in order to test the generalizability of our model. To conclude, this research provides some preliminary insights into the disruptive market phenomenon of spiritual branding being witnessed in India and offers a promising avenue for future research using multiple theoretical perspectives, such as social contagion theory, institutional theory, brand credibility, and/or brand association and value proposition. 


\section{REFERENCES}

Abela, A. V. (2014). Appealing to the imagination: Effective and ethical marketing of religion. Journal of Business Research, 67, 50-58.

Allport, G. W., \& Ross, J. M. (1967). Personal religious orientation and prejudice. Journal of Personality and Social Psychology, 5(4), 432-443.

Ames, P. (2013). Religion in Europe, also in crisis. Accessed on $18^{\text {th }}$ January 2018 https://www.pri.org/stories/2013-06-03/religion-europe-also-crisis .

Andersen, P. B., Gundelach, P., \& Lüchau, P. (2008). Religion in Europe and the United States. Nordic Journal of Religion and Society, 21(1), 61-74.

Arli, D., Cherrier, H., \& Tjiptono, F. (2016). God blesses those who wear Prada: Exploring the impact of religiousness on attitudes toward luxury among the youth of Indonesia. Market Intelligence \& Planning, 34(1), 61-79.

Arli, D., \& Tjiptono, F. (2014). The end of religion? Examining the role of religiousness, materialism, and long-term orientation on consumer ethics in Indonesia. Journal of Business Ethics, 123(3), 385-400.

Bartels, J., \& Hoogendam, K. (2011). The role of social identity and attitude toward sustainability brands in buying behaviors for organic products. Journal of Brand Management, 18, 697-708.

Berghuijs, J., Pieper, J., \& Bakker, C. (2013). Being 'Spiritual' and being 'Religious' in Europe: Diverging life orientations. Journal of Contemporary Religion, 28(1), 15-32.

Bhatt, S. (2016). Is India ready for a branded player in the $\$ 40$ billion religion and spirituality market? The Economic Times, $27^{\text {th }}$ July. 
Bullard, G. (2016). The world's newest major religion: No religion. Nationalgeographic.com, $22^{\text {nd }}$ April.

Bruce, S. (2002). God is dead. Oxford, UK: Blackwell Publishers.

Casidy, R., Phau, I., \& Lwin, M. (2016). Religiosity and digital piracy: An empirical examination. Services Marketing Quarterly, 37(1), 1-13.

Cavusgil, S. T., Ghauri, P. N., \& Akcal, A. A. (2013). Doing business in emerging markets (Second Edition). London: Sage Publishers.

CIA World Factbook (2017), "India”, CIA World Factbook, available at: https://www.cia.gov/library/publications/the-world-factbook/geos/in.html (accessed 16 October 2017).

Crabtree, V. (2015). Religion in Europe. Accessed on $18^{\text {th }}$ January 2018 http://www.humanreligions.info/europe.html.

Darvyri, P., Galanakis, M., Avgoustidis, A. G., Pateraki, N., Vasdekis, S., \& Darviri, C. (2014). The revised intrinsic/extrinsic religious orientation scale in a sample of Attica's inhabitants. Psychology, 5(13), 1557-1567.

Debien, N., \& Calderwood, K. (2016). 'Spiritual but not religious': What the census won't say about Australians' beliefs. ABC.net.au, $8^{\text {th }}$ August.

Deka, K. (2017). How Ramdev's business empire benefits from his proximity to the BJP. Scroll.in, $3^{\text {rd }}$ May.

Delaney, C. (2005). Development and psychometric testing of a holistic instrument to assess the human spiritual dimension. Journal of Holistic Nursing, 23(2), 145-167. 
Dutta, A. (2017). Ramdev's Patanjali shakes up FMCG order; next up 'nutritious restaurants'. Business Standard, $5^{\text {th }}$ May.

Einstein, M. (2008). Brands of faith: marketing religion in a commercial age. Oxford, UK: Routledge Publishing.

El-Bassiouny, N. (2014). The one-billion-plus marginalization: Toward a scholarly understanding of Islamic consumers. Journal of Business Research, 67, 42-49.

Engelland, B. T. (2014). Religion, humanism, marketing, and the consumption of socially responsible products, services, and ideas: Introduction to a special topic section. Journal of Business Research, 67, 1-4.

Fitzmaurice, J., \& Comegys, C. (2006). Materialism and social consumption. Journal of Marketing Theory and Practice, 14(4), 287-299.

Fornell, C., \& Larcker, D. F. (1981). Structural equation models with unobservable variables and measurement error: Algebra and statistics. Journal of Marketing Research, 18(3), 382-388.

Greene, W.H. 2003. Econometric analysis (5th Edition). Upper Saddle River, NJ: Prentice Hall.

Hair Jr, J. F., Anderson, R. E., Tatham, C. L., \& Black, W. C. (1992). Multivariate Data Analysis. New York, USA: Macmillan.

Hair, J. F. J., Black, W. C., Babin, B. J., \& Anderson, R. E. (2010). Multivariate Data Analysis (Seventh Edition). USA: Prentice Hall.

Hatch, R. L., Burg, M. A., Naberhaus, D. S., \& Hellmich, L. K. (1998). The spiritual involvement and beliefs scale: Development and testing of a new instrument. Journal of Family Practice, 46(6), 476-487. 
Hill, P. C., Pargament, K. I., Hood Jr., R. W., McCullough, M. E., Swyers, J. P., Larson, D. B., \& Zinnbauer, B. J. (2000). Conceptualizing religion and spirituality: Points of commonality, points of departure. Journal for the Theory of Social Behaviour, 30(1), $51-77$.

Huss, B. (2014). Spirituality: The emergence of a new cultural category and its challenge to the religious and the secular. Journal of Contemporary Religion, 29(1), 47-60.

Izberk-Bilgin, E. (2012). Infidel brands: Unveiling alternative meanings of global brands at the nexus of globalization, consumer culture, and Islamism. Journal of Consumer Research, 39(4), 663-687.

Jaggi, R., \& Ghosh, M. (2017). Consumer perception of Patanjali products: An analytical study. The IUP Journal of Brand Management, 14(1), 13-23.

Jamal, A., \& Sharifuddin, J. (2015). Perceived value and perceived usefulness of halal labeling: The role of religion and culture. Journal of Business Research, 68, 933-941.

Kapuscinski, A. N., \& Masters, K. S. (2010). The current status of measures of spirituality: A critical review of scale development. Psychology of Religion and Spirituality, 2(4), 191-205.

Katz, D. (1960). The functional approach to the study of attitudes. Public Opinion Quarterly, 24(2), 163-204.

Kothawade, S. (2015). Sri Sri and Ramdev: Adulterating spirituality with politics? Thecitizen.in, $3^{\text {rd }}$ July.

Kotler, P., \& Keller, K. L. (2009). Marketing Management (13 ${ }^{\text {th }}$ ed.). Upper Saddle River, NJ, USA: Pearson Prentice Hall. 
Kumar, V., Jain, A., Rahman, Z., \& Jain, A. (2014). Marketing through spirituality: A case of Patanjali Yogpeeth. Procedia - Social and Behavioral Sciences, 133, 481-490.

Ladhari, R., \& Tchetgna, N. M. (2016). Values, socially conscious behaviour and consumption emotions as predictors of Canadians' intent to buy fair trade products. International Journal for Consumer Studies, 41(6), 696-705.

Lee, R. L. M. (2003). The re-enchantment of the self: western spirituality, Asian materialism. Journal of Contemporary Religion, 18(3), 351-367.

Lipka, M., \& Gecewicz, C. (2017). More Americans now say they're spiritual but not religious. Pewresearch.org, $6^{\text {th }}$ September.

Lu, J, Yiu, A., \& Soman, A. (2016). Indian consumer close-up: Tapping the spending power of a young, connected urban mass. Goldman Sachs.

Maheshwari, R. (2017). The epic rise of Patanjali: Game-changer in Indian FMCG industry. Yourstory.com, $17^{\text {th }}$ March.

Maltby, J. (1999). The internal structure of a derived, revised, and amended measure of the religious orientation scale: The ‘Age-Universal' I-E scale- 12. Social Behavior and Personality, 27(4), 407-412.

Malviya, S. (2017). HUL makes new game plan, forms crack teams to knock the wind out of Patanjali's sale. The Economic Times, $19^{\text {th }}$ May.

Mathews, G. (2000). Global culture/individual identity: Searching for home in the cultural supermarket. London, UK: Routledge Publishing.

Mathras, D., Cohen, A. B., Mandel, N., \& Mick, D. G. (2016). The effects of religion on consumer behaviour: A conceptual framework and research agenda. Journal of Consumer Psychology, 26(2), 298-311. 
McAlexander, J. H., Dufault, B. L., Martin, D. M., \& Schouten, J. W. (2014). The marketization of religion: field, capital, and consumer identity. Journal of Consumer Research, 41(3), 858-875.

McFadden, D. (1974) Conditional logit analysis of qualitative choice behavior. In P. Zarembka, (Ed), Frontiers in econometrics. New York: Academic Press

Meyer, K. E. (2006). Asian management research needs more self-confidence. Asia-Pacific Journal of Management, 23(2), 119-137.

Meyer, K. E., \& Peng, M. W. (2016). Theoretical foundations of emerging economy business research. Journal of International Business Studies, 47, 3-22.

Mitra, S. (2017). Baba Ramdev's Patanjali eyes two-fold rise in sales at Rs. 20,000 crore in FY18. Live Mint, $4^{\text {th }}$ May.

Moore, R. L. (1995). Selling God: American religion in the marketplace of culture. UK: Oxford University Press.

Nielsen. (2012). Emerging consumer demand: Rise of the small town India. India: Nielsen and Confederation of Indian Industry.

Pargament, K. I. (1999). The psychology of religion and spirituality? Yes and No. The International Journal of the Psychology of Religion, 9(1), 3-16.

Patwardhan, A. M., Keith, M. E., \& Vitell, S. J. (2012). Religiosity, attitude toward business, and ethical beliefs: Hispanic consumers in the United States. Journal of Business Ethics, 110(1), 61-70.

Piedmont, R. L. (1999). Does spirituality represent the sixth factor of personality? Spiritual transcendence and the five-factor model. Journal of Personality, 67(6), 985-1013. 
Sanjai, P. R., \& Pradhan, B. (2016). India's bearded Yogis are snatching sales from Global brands. Bloomberg, $1^{\text {st }}$ December.

Sardana, D., \& Zhu, Y. (2017). Conducting business in China and India: A comparative and contextual analysis. London: Palgrave Macmillan.

Saucier, G., \& Skrzypińska, K. (2006). Spiritual but not religious? Evidence for two independent dispositions. Journal of Personality, 74(5), 1257-1292.

Shavitt, S. (1989). Products, personalities and situations in attitude functions: Implications for consumer behavior. Advances in Consumer Research, 16(1), 300-305.

Sharma, P. (2011). Country-of-Origin Effects in Developed vs. Emerging Markets: Exploring the Contrasting Roles of Materialism and Value-Consciousness. Journal of International Business Studies, 42(2), 285-306.

Shaw, D., \& Thomson, J. (2013). Consuming spirituality: The pleasure of uncertainty. European Journal of Marketing, 47(3/4), 557-573.

Singhi, A., Jain, N., \& Sanghi, K. (2017). The new India: The many facets of a changing consumer. The Boston Consulting Group.

Snyder, M., \& DeBono, K. G. (1985). Appeals to image and claims about quality: Understanding the psychology of advertising. Journal of Personality and Social Psychology, 49(3), 586-597.

Stillman, T. F., Fincham, F. D., Vohs, K. D., Lambert, N. M., Phillips, C. A. (2012). The material and immaterial in conflict: Spirituality reduces conspicuous consumption. Journal of Economic Psychology, 33, 1-7.

Stout, D. A. (2009). Book Review: Brands of faith: Marketing religion in a commercial age by Mara Einstein. Journal for the Scientific Study of Religion, 48(2), 404-405. 
Tsui, A. (2004). Contributing to global management knowledge: A case of high quality indigenous research. Asia-Pacific Journal of Management, 21(4), 491-513.

Vitell, S. J. (2009). The role of religiosity in business and consumer ethics: A review of the literature. Journal of Business Ethics, 90, 155-167.

Vitell, S. J., King, R. A., Howie, K., Toti, J. F., Albert, L., Hidalgo, E. R., \& Yacout, O. (2015). Spirituality, moral identity, and consumer ethics: A multi-cultural study. Journal of Business Ethics, 139(1), 147-160.

Voas, D., \& Crockett, A. (2005). Religion in Britain: Neither believing nor belonging. Sociology, 39(1), 11-28.

Wong, N. Y., \& Ahuvia, A. C. (1998). Personal taste and family face: Luxury consumption in Confucian and Western societies. Psychology \& Marketing, 15(5), 423-441.

World Population Review (2017), “India population 2017”, available at: http://worldpopulationreview.com/countries/india-population/ (accessed 16 October 2017)

Yang, S., \& Stening, B. W. (2013). Mao meets the market: Reconciling ideology and pragmatism in China. Management International Review, 53, 419-438.

Yang, S., \& Stening, B. W. (2016). Antecedents of materialism in China - an intergenerational analysis. International Journal of Consumer Studies, 40, 701-711.

Zinnbauer, B.J., Pargament, K. I., Cole, B., Rye, M. S., Butter, E. M., Belavich, T. G., Hipp, K. M., Scott, A. B., \& Kadar, J. L. (1997). Religious and Spirituality: Unfuzzying the fuzzy. Journal of the Scientific Study of Religion, 36(4), 549-564. 


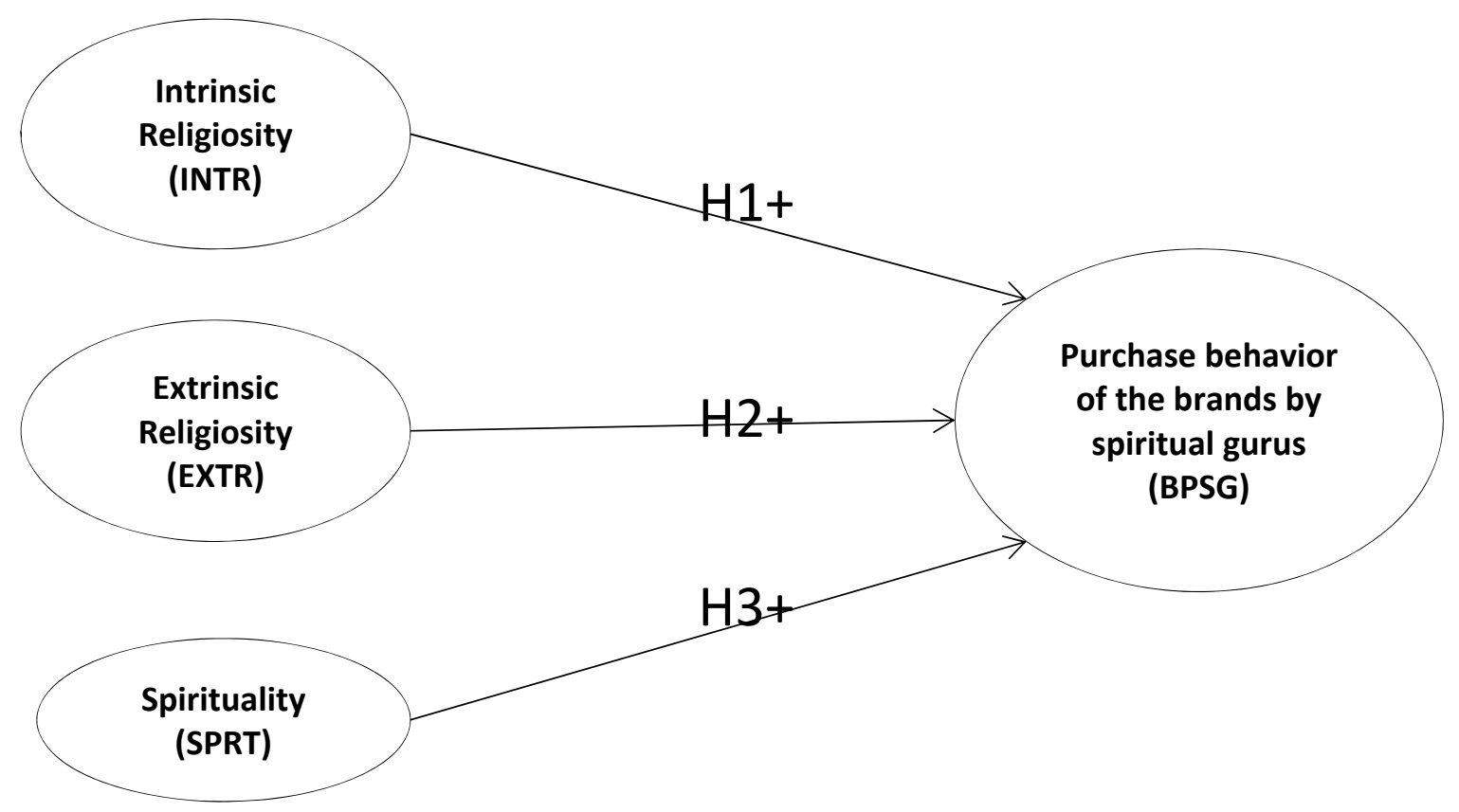

FIGURE 1 The theoretical framework 
TABLE 1 Sample profile

\begin{tabular}{llc}
\hline Variables & Levels & Percentages \\
\hline Gender & Male & $76.4 \%$ \\
Age & Female & $23.5 \%$ \\
\cline { 2 - 3 } & Less than 21 years & $0.4 \%$ \\
& $21-30$ years & $52.1 \%$ \\
& $31-40$ years & $37.4 \%$ \\
& $41-50$ years & $7.6 \%$ \\
& $51-60$ years & $1.7 \%$ \\
Education Level & more than 60 years & $0.8 \%$ \\
\cline { 2 - 3 } & High School or less & $0.4 \%$ \\
& Graduate & $48.3 \%$ \\
& Post Graduate or more & $51.3 \%$ \\
\hline
\end{tabular}


TABLE 2 Scale items and psychometric properties

\begin{tabular}{|c|c|c|c|c|}
\hline Item\# & Item Description & Mean & SD & $\begin{array}{c}\text { Factor } \\
\text { Loading }\end{array}$ \\
\hline F1: & Intrinsic religiosity (Cronbach's $\alpha=0.80$ ) & 3.90 & 1.32 & \\
\hline F1-1 & I often hear religious sermons, talks or prayers on $\mathrm{TV}$, radio or in person & 3.11 & 1.72 & 0.76 \\
\hline F1-2 & I live life according to my religious beliefs and follow rituals & 4.25 & 1.74 & 0.76 \\
\hline F1-3 & I often go to a religious place & 4.20 & 1.82 & 0.71 \\
\hline F1-4 & What religion offers me most is comfort in times of trouble and sorrow & 3.94 & 1.82 & 0.62 \\
\hline F1-5 & I enjoy reading books about my religion & 4.04 & 1.78 & 0.62 \\
\hline F2: & Extrinsic religiosity (Cronbach's $\alpha=0.87$ ) & 2.96 & 1.43 & \\
\hline F2-1 & I go to a religious service because it helps me to make friends & 2.82 & 1.63 & 0.91 \\
\hline F2-2 & I go to a religious service because I enjoy interacting with people there & 3.37 & 1.76 & 0.82 \\
\hline F2-3 & I go to a religious service because it helps me to feel socially secured and cared for & 3.21 & 1.87 & 0.81 \\
\hline F2-4 & I enjoy interacting with friends in a religious service more than my other friends & 2.44 & 1.50 & 0.74 \\
\hline F3: & Spirituality (Cronbach's $\alpha=0.75)$ & 4.90 & 1.22 & \\
\hline F3-1 & I believe there is a connection between all things that I cannot see but can sense & 5.15 & 1.46 & 0.82 \\
\hline F3-2 & I believe in a Higher Power/Universal Intelligence & 5.44 & 1.49 & 0.79 \\
\hline F3-3 & I meditate to gain access to my inner spirit & 4.61 & 1.74 & 0.68 \\
\hline F3-4 & I have a relationship with a Higher Power/Universal Intelligence & 4.37 & 1.70 & 0.66 \\
\hline
\end{tabular}


TABLE 3 Correlations and variance matrix

\begin{tabular}{lcccc}
\hline Factors & INTR & EXTR & SPRT & BPSG \\
\hline Intrinsic religiosity (INTR) & 0.70 & & \\
Extrinsic religiosity (EXTR) & $0.40^{* *}$ & 0.82 & & \\
Spirituality (SPRT) & $0.36^{* *}$ & $0.14^{*}$ & 0.74 & \\
Purchase of brands promoted by & & & & \\
spiritual gurus (BPSG) & $0.19^{* *}$ & $0.18^{* *}$ & 0.01 & - \\
\hline Mean & 3.90 & 2.95 & 4.89 & 0.49 \\
Standard deviation & 1.32 & 1.42 & 1.21 & 0.82 \\
Average variance extracted (AVE) & 0.49 & 0.68 & 0.55 & - \\
Composite Reliability & 0.82 & 0.89 & 0.83 & - \\
\hline Note: Figures on the diagonal are square root of AVE; $* * \mathrm{p}<.01, * \mathrm{p}<.05$ &
\end{tabular}

TABLE 4 Independent variables - descriptive, and ANOVA results

\begin{tabular}{llccccc}
\hline Factors & Type of Brands & Mean & SD & Sample & F Stat & F Sig \\
\hline INTR & Regular Brands & 3.74 & 1.31 & 159 & $\mathbf{7 . 4 7}$ & $\mathbf{0 . 0 0 0}$ \\
& Spiritual Brands & 4.23 & 1.31 & 79 & & \\
\hline EXTR & Regular Brands & 2.78 & 1.35 & 159 & $\mathbf{7 . 8 8}$ & $\mathbf{0 . 0 0 0}$ \\
& Spiritual Brands & 3.32 & 1.53 & 79 & & \\
\hline \multirow{2}{*}{ SPRT } & Regular Brands & 4.89 & 1.19 & 159 & 0.01 & 0.921 \\
& Spiritual Brands & 4.90 & 1.28 & 79 & & \\
\hline
\end{tabular}

Note:

- Spiritual Brands: The consumers choosing the brands promoted by spiritual gurus for at least one of the four products.

- Regular Brands: The consumers choosing the regular brands for all the four products

TABLE 5 Sample cross tabulation between factors and their levels

\begin{tabular}{|c|c|c|c|c|}
\hline \multicolumn{2}{|c|}{$\begin{array}{c}\text { Sample Size (Number of } \\
\text { responses) }\end{array}$} & Intrinsic religiosity & Extrinsic religiosity & Spirituality \\
\cline { 2 - 5 } & High $(\mathbf{X}>\mathbf{5})$ & 44 & 16 & 101 \\
\hline \multirow{2}{*}{$\begin{array}{c}\text { Degree of } \\
\text { the factor }\end{array}$} & Med $(\mathbf{5}>=\mathbf{X}>\mathbf{4})$ & 87 & 63 & 96 \\
\cline { 2 - 5 } & Low $(\mathbf{X}<=\mathbf{4})$ & 107 & 159 & 41 \\
\hline
\end{tabular}


TABLE 6 Multinomial logistic regression results

\begin{tabular}{|c|c|c|c|c|c|c|c|}
\hline \multirow{3}{*}{$\begin{array}{l}\text { Variables } \\
\end{array}$} & \multirow[b]{3}{*}{ Levels } & \multicolumn{6}{|c|}{$\begin{array}{c}\text { Degree of preference of brands offered by the spiritual gurus in comparison to } \\
\text { any other brand }\end{array}$} \\
\hline & & \multicolumn{3}{|c|}{ For One Food Product } & \multicolumn{3}{|c|}{ For More than One Food Products } \\
\hline & & Beta & Sig. & $\operatorname{Exp}(B)$ & Beta & Sig. & $\operatorname{Exp}(B)$ \\
\hline & Intercept & 0.86 & 1.00 & & 11.08 & 0.99 & \\
\hline \multirow{4}{*}{ Intrinsic religiosity } & High & -0.18 & 0.75 & 0.83 & 1.32 & 0.05 & 3.76 \\
\hline & Med & 0.02 & 0.96 & 1.02 & 0.61 & 0.31 & 1.83 \\
\hline & Low & ob & & & $0 \mathrm{~b}$ & & \\
\hline & High & 2.20 & $\mathbf{0 . 0 0}$ & 8.98 & 0.71 & 0.48 & 2.04 \\
\hline \multirow[t]{3}{*}{ Extrinsic religiosity } & Med & 0.19 & 0.66 & 1.21 & 0.54 & 0.34 & 1.71 \\
\hline & Low & $0 \mathrm{~b}$ & & & ob & & \\
\hline & High & -0.03 & 0.96 & 0.97 & -0.21 & 0.77 & 0.82 \\
\hline \multirow{4}{*}{ Spirituality } & Med & 0.50 & 0.35 & 1.65 & -0.73 & 0.33 & 0.48 \\
\hline & Low & $0 \mathrm{~b}$ & & & $0 \mathrm{~b}$ & & \\
\hline & Less than 0.5 & 0.82 & 0.35 & 2.26 & 1.45 & 0.24 & 4.28 \\
\hline & $0.5-1$ & 0.59 & 0.41 & 1.81 & 1.67 & 0.10 & 5.29 \\
\hline \multirow{5}{*}{$\begin{array}{l}\text { Annual Family Income } \\
\text { (in Million INR) }\end{array}$} & $1-1.5$ & 0.43 & 0.54 & 1.54 & 0.40 & 0.69 & 1.48 \\
\hline & $1.5-2.0$ & 0.75 & 0.29 & 2.11 & 1.21 & 0.21 & 3.36 \\
\hline & $2.0-2.5$ & 1.45 & 0.08 & 4.25 & 0.10 & 0.95 & 1.10 \\
\hline & $2.5-3.0$ & 1.54 & 0.07 & 4.65 & 0.79 & 0.59 & 2.19 \\
\hline & More than 3.0 & $0 \mathrm{~b}$ & & & $0 \mathrm{~b}$ & & \\
\hline \multirow{3}{*}{ Gender } & Male & -0.09 & 0.82 & 0.91 & 1.50 & $\mathbf{0 . 0 7}$ & 4.47 \\
\hline & Female & $0 \mathrm{~b}$ & & & $0 \mathrm{~b}$ & & \\
\hline & Less than 21 years & -27.09 & 0.98 & - & -28.78 & 0.99 & - \\
\hline \multirow{5}{*}{ Age } & $21-30$ years & -14.57 & 0.99 & - & -15.18 & 0.99 & - \\
\hline & $31-40$ years & -14.90 & 0.99 & - & -13.53 & 0.99 & - \\
\hline & $41-50$ years & -15.48 & 0.99 & - & -13.64 & 0.99 & - \\
\hline & $51-60$ years & -27.50 & 0.98 & - & -26.45 & 0.98 & - \\
\hline & more than 60 years & ob & & & $0 b$ & & \\
\hline
\end{tabular}




\begin{tabular}{llrrrrrr} 
& & & 11.93 & 0.99 & $1,52,371$ & -0.82 & 0.63 \\
Marital Status & Unmarried & 12.44 & 0.99 & $2,53,358$ & -1.38 & 0.37 & 0.44 \\
& Married & $0 \mathrm{~b}$ & & & $0 \mathrm{~b}$ & 0.25 \\
& Divorced & -2.26 & & 0.11 & 16.88 & 1.00 & $2,14,19,769$ \\
\hline \multirow{3}{*}{ Education } & High School or Less & $\mathbf{- 0 . 8 9}$ & $\mathbf{0 . 0 2}$ & 0.41 & -0.53 & 0.34 & 0.59 \\
& Graduates & $0 \mathrm{~b}$ & & & $0 \mathrm{~b}$ & \\
\hline
\end{tabular}

